\title{
La demeure seigneuriale dans l'espace Plantagenêt
}

\section{Vincent Carpentier}

\section{OpenEdition}

\section{Journals}

Édition électronique

URL : http://journals.openedition.org/rao/2233

DOI : $10.4000 /$ rao.2233

ISBN : 978-2-7535-3432-2

ISSN : 1775-3732

Éditeur

Presses universitaires de Rennes

Édition imprimée

Date de publication : 25 décembre 2013

Pagination : $317-318$

ISBN : 978-2-7535-3430-8

ISSN : 0767-709X

\section{Référence électronique}

Vincent Carpentier, «La demeure seigneuriale dans l'espace Plantagenêt », Revue archéologique de I'Ouest [En ligne], 30 | 2013, mis en ligne le 25 décembre 2013, consulté le 03 décembre 2020. URL http://journals.openedition.org/rao/2233 ; DOl : https://doi.org/10.4000/rao.2233

Ce document a été généré automatiquement le 3 décembre 2020.

Tous droits réservés 


\title{
La demeure seigneuriale dans l'espace Plantagenêt
}

\author{
Vincent Carpentier
}

\section{RÉFÉRENCE}

Meirion-Jones G., 2013 - La demeure seigneuriale dans l'espace Plantagenêt. Salles, chambres et tours, Rennes, PUR, coll. « Art \& Société », 2013, 485 p. (ISBN 978-2-7535-2113-1)

1 À l'ombre des géants du Moyen Âge, châteaux-forts, abbayes et autres cathédrales qui ont monopolisé l'attention des antiquaires ou des historiens de l'art et de l'architecture depuis le milieu du $\mathrm{XIX}^{\mathrm{e}}$ siècle, ce volumineux ouvrage collectif dirigé par l'éminent Gwyn Meirion-Jones, professeur émérite de géographie à la London Metropolitan University, est dédié aux constructions domestiques médiévales de l'espace Plantagenêt. Le propos s'inscrit d'emblée dans une perspective interdisciplinaire faisant appel à l'archéologie des élévations, aux indispensables recherches en archives, ainsi qu'à la dendrochronologie. La matière réunie dans les 450 pages de ce bel ouvrage est le fruit d'un travail de longue haleine, entamé dans les années 1980 par une équipe internationale de chercheurs issus de ce « monde Plantagenêt » qui couvre l'Angleterre en son entier depuis les marches écossaises jusqu'aux Pyrénées, incluant ainsi toute la façade atlantique de la France comprise entre le pays de Caux et la Gascogne, jusqu'à l'Auvergne à l'est. Point n'est question ici de définir un hypothétique style architectural homogène qui serait propre à ce vaste ensemble dynastique, en substance plutôt bigarré. Bien au contraire : la perméabilité des frontières en matières de styles, de techniques ou de traditions; la vigueur des courants d'échanges et de diffusion des matériaux, des modes et des savoir-faire forment le fil directeur de cette somme plurielle, entendue comme une mosaïque d'études inter complémentaires et variées en termes d'objets, de méthodes ou d'échelles.

2 L'ensemble des acquis présentés dans ce livre forme un tout considérable : il s'agit de retracer sinon réécrire tout un pan de l'histoire de l'architecture civile aristocratique 
de la Grande-Bretagne et de la France du XI $\mathrm{Xu}^{\mathrm{e}} \mathrm{xv}^{\mathrm{e}}$ siècle. Le plan adopté, conçu sur le principe d'une déclinaison géographique, rend clairement compte de la diversité des sources et des études. Un petit ensemble de contributions s'attache à décrire l'évolution des formes architecturales et des matériaux utilisés dans une région donnée : nord et sud de l'Angleterre (Ph. Dixon); Bretagne, Maine et Anjou (J.-Cl. Meuret; G. MeirionJones, M. Jones et F. Guibal), sud-ouest de la Normandie (D. Nicolas-Méry). Un autre ensemble plus copieux regroupe tantôt des monographies d'édifices pas ou peu étudiés jusqu'alors, tantôt des études consacrées à de petits ensembles résidentiels, manoirs ruraux, palais épiscopaux ou moulins fortifiés, issus du Maine et de Vendée, de Touraine, de Beauce et du Sud-Ouest français. Certaines parties spécifiques de l'habitation donnent également lieu à des études particulières, comme la chambre de retrait en France vers 1350-1450 (A. Salamagne), la salle des manoirs angevins du XII à la fin du $\mathrm{XV}^{\mathrm{e}}$ siècle (G. Carré et $\mathrm{E}$. Litoux), ou les charpentes de comble et de plancher angevines (J.-Y. Hunot). Il en va de même pour les programmes architecturaux développés par le roi René en Anjou (E. Litoux) ou les Plantagenêt eux-mêmes en Quercy (G. Séraphin). Si la plupart des sites s'inscrit dans un contexte seigneurial et rural, l'ouvrage délivre également d'importantes informations sur les résidences des élites princières, avec la grande salle des ducs de Normandie au château de Caen (E. Impey, J. McNeill); celles de la bourgeoisie urbaine (P. Garrigou Grandchamp); ou encore les demeures d'ecclésiastiques. Il est aussi spécifiquement question de méthodologie dans un article dédié aux applications de la dendrochronologie à l'histoire des grandes salles en bois de l'Angleterre (E. Impey). L'ensemble des contributions témoigne par ailleurs d'une étroite prise en compte des évolutions sociales et culturelles associées aux aménagements de confort, d'hygiène ou d'intimité, qui acquièrent une importance croissante au fil de la période considérée, lisible en particulier dans l'ameublement dont témoignent les archives explorées par M. Nassiet.

Cet ouvrage distille une masse considérable d'informations répondant à l'ampleur de ce sujet ambitieux, conçu en ouverture sur l'avenir et autour d'une interdisciplinarité revendiquée qui ne relève pas ici d'un simple effet de mode mais s'inscrit dans un travail collectif entamé depuis plus de trente ans. Les données réunies depuis les années 1980 viennent ainsi consolider et enrichir les publications antérieures dirigées par Gwyn Meirion-Jones sur les architectures médiévales anglaise et bretonne ou les apports de la dendrochronologie à l'histoire des charpentes. L'ouvrage se pare en outre d'une séduisante qualité de présentation. L'illustration y est abondante et fort soignée, incluant cartes, plans et photographies en couleurs. Deux index bien utiles, nominatif et thématique, ont été joints à la fin du volume. La bibliographie, abondante, est regroupée à la fin de chaque contribution; l'avant-propos et l'introduction fournissent un certain nombre de remarques et de références d'ensemble, au nombre desquelles on s'étonne cependant de ne pas retrouver les travaux importants de Frédéric Épaud, qu'il s'agisse de sa thèse monumentale sur les charpentes normandes, parue à Caen aux Publications du Crahm en 2007, et citée ailleurs dans l'ouvrage, ou bien de ses articles récents consacrés à diverses architectures de l'Ouest de la France. Malgré cet oubli, auquel tout un chacun pourra aisément remédier, voici en somme un beau et conséquent ouvrage dont la lecture s'avère indispensable aux archéologues comme aux historiens de la construction et de l'habitation médiévales. 


\section{AUTEURS}

VINCENT CARPENTIER

Inrap Basse-Normandie 